\title{
Direct Interventional Discussion Effectively Improves Awareness and Knowledge about Modern Contraceptive Methods
}

\author{
Abdelhaseib S. Saad1', Amr Sharafeldeen² \\ ${ }^{1}$ Departments of Obstetrics \& Gynecology, Faculty of Medicine, Menoufia Universities, Al Minufya, Egypt \\ ${ }^{2}$ Departments of Obstetrics \& Gynecology, Faculty of Medicine, Benha Universities, Benha, Egypt \\ Email: amr.sharafeldin20018@gmail.com
}

How to cite this paper: Saad, A.S. and Sharafeldeen, A. (2020) Direct Interventional Discussion Effectively Improves Awareness and Knowledge about Modern Contraceptive Methods. Advances in Reproductive Sciences, 8, 1-13.

https://doi.org/10.4236/arsci.2020.81001

Received: November 5, 2019

Accepted: December 15, 2019

Published: December 18, 2019

Copyright $\odot 2020$ by author(s) and Scientific Research Publishing Inc. This work is licensed under the Creative Commons Attribution International License (CC BY 4.0).

http://creativecommons.org/licenses/by/4.0/

(c) (i) Open Access

\begin{abstract}
Objectives: Determination of influence of direct interview of postpartum women about their awareness and knowledge regarding contraception and modern contraceptive methods. Patients \& Methods: 1437 women joined the intervention and underwent evaluation of their knowledge about the concept and methods of contraception. Then, an interview was conducted with each woman to clarify advantages and appropriateness of various contraceptives and the proper time for initiation of contraception. All women were asked to discuss these data with their families and return to give their decision. Study outcomes included evaluation of women's knowledge about contraception and its modalities, frequency of non-users who accepted to use contraception and is considered as success of the intervention and frequency of requesting each modality of contraception. Results: TV programs and discussion with local health provider, relatives or friends are the main sources of knowledge of primiparas. 182 primiparas had good knowledge and chose the appropriate method of contraception during the 1st session of discussion, and 81 primiparas required $>2$ sessions to choose the method appropriate for them, while 21 primiparas insisted not to use contraception for an acceptance rate of $92.6 \%$ among primipara. Among multiparas, 222 multiparas were non-users, but after discussion 133 couples accepted to use contraception. Thus, 396 non-users had accepted to use contraception for an intervention success rate of $78.3 \%$. Collectively 692 women (52.1\%) received IUD and 635 women (47.9\%) received hormonal contraception; 432 orally (32.6\%) and 203 parenterally (15.3\%). Conclusion: Ignorance, low financial status and cultural beliefs deleteriously affect knowledge about contraception options and its methods, so direct interview is mandatory. The applied intervention succeeded to replenish women's knowledge about benefits of using contraception. Primiparas had knowledge about contraception but their knowledge
\end{abstract}


about methods is deficient or hazy. Contraception using IUD is the most acceptable method especially for primiparas.

\section{Keywords}

Knowledge, Contraception, Modern Methods, Primiparas, Intrauterine Device

\section{Introduction}

Worldwide population growth is a great problem that can slow or prevent economic and social development in most developing countries [1] and affected different social groups especially mothers and infants [2].

Safe and effective contraception is the most important prerequisite for women who wish to delay or avoid pregnancy [3]. The use of contraception was associated with reductions in crude birth rate, maternal and neonatal morbidity, and the number of women with high-risk pregnancies giving birth [2]. Contraceptive methods choice increased over recent years, but not all available methods are appropriate for all women, especially those had medical problems [4]. However, socioeconomic changes [5], as well as the development of new contraceptive modalities may influence women's preferences in the selection of contraceptive method [6].

Levels of modern contraceptive knowledge and use vary among women according to socioeconomic status [7], educational level [8], residence in rural or urban areas [9].

Despite the reality that, individuals should be able to have a sex life that is both satisfying and safe, and be free in decision-making concerning timing to have children [10], women spend most of their reproductive years avoiding pregnancy [11]. Thus, the access to information and contraceptive methods should be ensured by the healthcare system, to promote the responsible and equitable exercise of these rights [1].

However, numerous challenges in providing effective, seamless service provision of contraception after pregnancy are reported even in industrialized countries [12]. Timing of insertion of intrauterine devices in relation to time of labor was one challenge, WHO [13] does not recommend insertion between 48 hours and 4 weeks after childbirth because of higher rates of expulsion compared with later interval insertion; however, the USMEC [14] considers that the benefit of insertion at this time outweighs the risks. Moreover, expulsion rates of expulsion were higher for the LNGIUS than for copper devices inserted before 4 weeks and after vaginal delivery were 5 times higher than after insertion at the time of cesarean section [15].

Moreover, review of literature detected limited electronic interventions for improving contraceptive knowledge attitude toward contraception, contraceptive method choice, contraceptive use, or pregnancy [16], so formal interventions are needed to improve the efficacy of contraceptive education [17]. 


\subsection{Objectives}

This interventional study aimed to determine the influence of direct interview of postpartum women attending the outpatient clinic (OPC) about their awareness and knowledge regarding contraception and modern contraceptive methods.

\subsection{Design}

Prospective multicenter clinical trial.

\subsection{Setting}

Departments of Obstetrics \& Gynecology, Faculty of Medicine, Menoufia and Benha Universities.

\section{Patients \& Methods}

The current study intended to collect all women attending OPC at the university hospitals included in the study since Jan 2016 till Jan 2019. The study depended on direct interview, which is the most convenient method for supplying knowledge especially in underdeveloped countries characterized by illiteracy especially that concerned with social communication modalities.

At the 1st visit, socio-demographic data of attendants including age, religion, residence, degree of education, financial status, type of work and type of lifestyle, and obstetric history included inquire about age of marriage, age at time of the first pregnancy, number of previous pregnancies, labors and living offspring were recorded. Then, all women were asked to answer questions concerning their knowledge and rational about contraception by choosing either one of a five-point Likert scale including disagree completely/disagree/neither do not agree nor disagree/agree/agree completely [18] except some questions that required the answer by yes or no. The used questionnaire, as shown in Appendix 1, was constructed according to items used by Hogmark et al. [19] and adopted for Egyptian women.

After evaluation of women's knowledge, an interview was conducted with each woman to clarify the advantages and appropriateness of various contraceptives and the proper time for initiation of contraception. All women were allowed to ask and discuss their knowledge about each contraceptive modality and full explanations and detailed answers were provided to get their confidence and so as to accept the correct option. All women were given a time space to discuss the provided data with their husbands or nearby relatives and to return to the clinic to give their decision. The previously described protocol was approved by the Local Ethical Committee and only women who signed written fully informed consent about the study target were enrolled in the study.

\section{Study Outcomes}

1) Primary outcome is the evaluation of women's knowledge about contraception and its various modalities. 
2) Secondary outcomes included determination of the frequency of

a) Women using contraceptive methods (Users).

b) Non-users who accepted to use contraception and is considered as success of the interventional interview.

c) Requesting each modality of contraception.

\section{Results}

During the study period, 1785 women were eligible for evaluation; 103 refused to sign the consent and 245 women escaped after the 1st meeting and were excluded, so 1437 women $(80.5 \%)$ joined the intervention and their socio-demographic and obstetric data are shown in Table 1. All intervention joining women had desire to get more children, irrespective of being primipara or multipara.

Primiparas had knowledge about the concept of contraception through TV programs $(n=235)$, discussion with local health provider $(n=167)$, nearby relatives or friends $(n=119)$ and online educational programs $(n=47)$; for a rate of knowledge sources/woman of 2 sources. Regarding the quality of knowledge of primiparas, 182 primiparas (64.1\%) had good knowledge that allowed them to choose the method of contraception appropriate for them during the 1st session of discussion, while 102 primiparas (35.9\%) had hazy knowledge and those received two discussion sessions about the health, family and economic benefits of contraception to allow proper family planning and adjusted spacing between offspring and were asked to discuss these data with their husband. On the next visit, 81 of those 102 primiparas (79.4\%) were ready to choose the appropriate modality for contraception, while the remaining 21 primiparas insisted not to use contraception and attributed such decision to their husbands, or families. Thus, the discussion intervention with primipara women resulted in an acceptance rate of $92.6 \%$.

Concerning the multiparas (Figure 1), 931 multiparas (80.7\%) are users, while the remaining 222 multiparas (19.3\%) are non-users. Out of these 222 multiparas, 107 multiparas (48.2\%) are non-users because of using safe-period, 67 multiparas (25.7\%) because of their husbands' refusal and 48 multiparas (25.7\%) are non-user for getting more pregnancies to get a male offspring. Discussion with these 222 couples about the availability, efficacy and safety of modern contraceptive methods was successful and 133 couples (60\%) accepted to use contraception, while 89 couples were still refusing to use contraception. Thus, 396 non-users; 133 multiparas and 263 primiparas, had accepted to use contraception and represent an intervention success rate of $78.3 \%$.

Among users 485 women (52.1\%) used IUD, 309 women (33.2\%) used contraceptive pills and 137 women (14.7\%) used injectable contraception. One hundred and thirty-eight multiparas (14.8\%) were less satisfied by their method of contraception; 71 women (51.4\%) who were pills' users complained of breast engorgement and mid-cyclic spotting and 23 of them (32.4\%) complained of heavy menses, 55 women (39.9\%) who were users of IUD had recurrent abdominal 
Table 1. Socio-demographic and obstetric data of enrolled women.

\begin{tabular}{|c|c|c|c|}
\hline \multicolumn{3}{|c|}{ Variables } & Findings \\
\hline \multicolumn{4}{|c|}{ Socio-demographic data } \\
\hline \multirow{5}{*}{\multicolumn{2}{|c|}{ Age (years) }} & $20-24$ & $125(8.7 \%)$ \\
\hline & & $25-29$ & $462(32.2 \%)$ \\
\hline & & $30-34$ & $568(39.5 \%)$ \\
\hline & & $35-39$ & $209(14.5 \%)$ \\
\hline & & $>40$ & $73(5.1 \%)$ \\
\hline \multirow{2}{*}{\multicolumn{2}{|c|}{ Religion }} & Muslim & $1309(91.1 \%)$ \\
\hline & & Christian & $128(8.9 \%)$ \\
\hline \multirow{5}{*}{\multicolumn{2}{|c|}{ Education }} & Illiterate & $89(6.2 \%)$ \\
\hline & & Primary school graduate & $232(16.1 \%)$ \\
\hline & & Secondary school graduate & $644(44.8 \%)$ \\
\hline & & College graduate & $393(27.3 \%)$ \\
\hline & & Post-college graduate & $79(5.5 \%)$ \\
\hline \multirow{4}{*}{\multicolumn{2}{|c|}{ Occupation }} & Farmer & $208(14.5 \%)$ \\
\hline & & Worker & $413(28.7 \%)$ \\
\hline & & Housewife & $541(37.6 \%)$ \\
\hline & & Officer & $275(19.6 \%)$ \\
\hline \multirow{4}{*}{\multicolumn{2}{|c|}{ Financial status }} & Very poor & $126(10 \%)$ \\
\hline & & Poor & $358(30 \%)$ \\
\hline & & Middle & $810(56.4 \%)$ \\
\hline & & Rich & $143(3.6 \%)$ \\
\hline \multicolumn{4}{|c|}{ Obstetric data } \\
\hline \multirow{2}{*}{\multicolumn{2}{|c|}{ Parity }} & Primipara & $284(19.8 \%)$ \\
\hline & & Multipara & $1153(80.2 \%)$ \\
\hline \multirow{4}{*}{\multicolumn{2}{|c|}{ Living offspring }} & 1 & $352(24.5 \%)$ \\
\hline & & 2 & $419(29.2 \%)$ \\
\hline & & 3 & $552(38.4 \%)$ \\
\hline & & 4 & $114(7.9 \%)$ \\
\hline \multirow{8}{*}{$\begin{array}{l}\text { Last pregnancy } \\
\text { data }\end{array}$} & Antenatal care visits & No & $384(26.7 \%)$ \\
\hline & & $<4$ & $839(58.4 \%)$ \\
\hline & & $>4$ & $214(14.9 \%)$ \\
\hline & Pregnancy-related & Yes & $279(19.4 \%)$ \\
\hline & complicati & No & $1158(80.6 \%)$ \\
\hline & Place of delivery & Home & $187(13 \%)$ \\
\hline & & Governmental institute & $754(52.5 \%)$ \\
\hline & & Private institute/clinic & $496(34.5 \%)$ \\
\hline
\end{tabular}

Data are presented as mean $\pm \mathrm{SD}$, numbers, and percentages. 


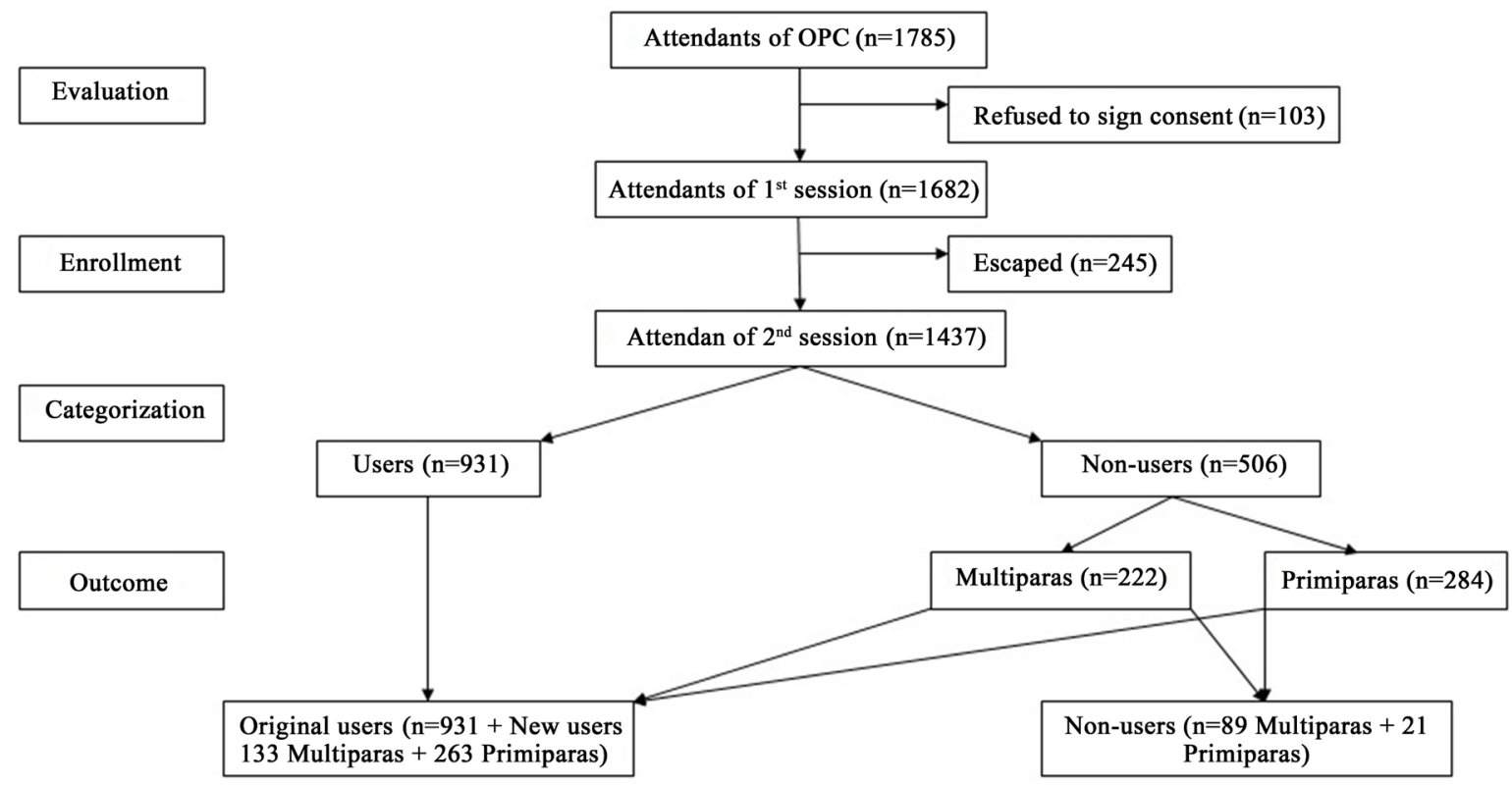

Figure 1. Consort flow chart.

pain, menstrual irregularities, heavy menses, frequent vaginal discharge or occasional failure to find the threads. Twelve of women (8.7\%) who were using injectable contraception complained of post-contraception amenorrhea. These 138 women underwent clinical, laboratory and US evaluation and the appropriate contraceptive method was provided for each according to the findings. Women complained of heavy menses on IUD received levonorgestrel intrauterine system, women used pills and those complained of amenorrhea on injectable contraceptive injection were shifted to cupper IUD.

Two-hundreds and seven; 67 multiparas and 140 primiparas, of newly users (52.2\%) chose IUD as the preferable method for contraception, while 123 women; 24 multiparas and 99 primiparas, requested for oral hormonal contraceptives and 66 women; 42 multiparas and 24 primiparas, accepted to used injectable hormonal contraception. Thus, collectively 692 women (52.1\%) received IUD and 635 women (47.9\%) received hormonal contraception; 432 orally (32.6\%) and 203 parenterally (15.3\%).

\section{Discussion}

The study depended on direct interview, which is the most convenient method for supplying knowledge especially in underdeveloped countries characterized by illiteracy. In line with this methodology, multiple similar studies were previously conducted using direct interview and questionnaire evaluation [20] [21] [22] [23] [24] (Elkalmi). The sources of knowledge about contraception among primiparas were variable and included TV programs, discussion with local health provider, nearby relatives or friends and online educational programs for a median number of sources/woman of 2 sources. In line with these findings, Ajong et al. [25] found that the main sources of information about contraception 
were the health personnel (47.7\%) and the school (23.6\%). Recently, Dut \& Al [26] found $43.5 \%$ of study participants received their knowledge about family planning and contraceptive methods from local health clinics.

Interestingly, only $4 \%$ of primiparas had their knowledge through online educational programs. This finding points to either the less interest in receiving knowledge through social media, less trust in this source of knowledge or lack of access to social media. On contrary, to these findings, Kofinas et al. [27] found social media as an adjunct to traditional in-office counseling improves patient contraceptive knowledge. On the other hand, and in line with the results of the current study, Byker et al. [28] performed an informational campaign carried out on social media for the use of long-acting reversible contraception and found the intervention did not have a detectable impact in the four months after the advertising campaign.

Regarding the quality of knowledge among primiparas, 182 primiparas (64.1\%) had good quality of knowledge that allowed them to take a decision about the use and method of contraception during the 1st session of discussion, while 102 primiparas (35.9\%) had hazy knowledge required more than one session for discussion of the benefits of contraception. Similarly, Gosavi et al. [29] found Singaporean women have poor awareness and knowledge of contraception and on counselling many (90.1\%) rated healthcare professional's advice as important in contraceptive choice.

At start and end of intervention, the percentages of women who chose IUD, contraceptive pills or injections were nearly similar; a finding that indicates the effects of previous knowledge concerning each contraceptive method and the impact of cultural believes on the choice of the method to be used. In support of this assumption, non-users who were accepted to use contraceptives had chosen the methods commonly used by users. Similarly, Gosavi et al. [29] detected that peer influence $(21 \%)$ and cultural practices (16.3\%) are important in contraceptive choice.

Women who had chosen IUD or injectable contraception attributed their choice to the fear of missing a pill or to their inability to follow regular pattern in their daily life and so a method that to be used once is appropriate to them. For a second time this opinion reflected the effect of the previous knowledge and the impact of social believes, and go in hand with Cohen et al. [30] who found 51\% of their study population chose IUD, $48 \%$ chose etonogestrel implant, $43 \%$ chose injectable drugs and $25 \%$ chose progestin-only pill as safe to use during lactation. Moreover, Castleberry et al. [31] examined obstetrician-gynecologist's practices regarding provision of contraceptive methods and found $91 \%$ of them reported providing IUDs, and $29 \%$ offered same-day placement.

On contrary to these findings, Ajong et al. [25] found the most cited contraceptive methods were oral pills (71.2\%) and implants (54.8\%) and Vigoureux \& Le Guen [32] found 72\% of French women were using pills and other hormonal contraceptives, IUD, but pills remain the first contraceptive method of choice. 
Among HIV-positive Ethiopian women, Alene \& Atalell [33], reported that the prevalence of contraceptive use is low, which suggests a high risk of unintended pregnancy, and injectable and male condoms are the most preferred type of contraceptive methods.

Twenty-one primiparas (20.6\%) refused to use contraception, even after two sessions of discussion and attributed such decision to their husbands, or families. This fining illustrates the impact of cultural believes on family planning-decision making. Similarly, Ajong et al. [25] reported that about $31 \%$ of current contraceptive non-users had no desire of adopting a contraceptive method in the future. Also, Shahabuddin et al. [34] found decision-making towards contraceptive methods use and childbearing among adolescent girls were mainly made by either their husbands or mothers-in-law especially with unemployed husbands who were financially dependent on their parents. Recently, Willcox et al. [35] suggested that the traditional believes as postponing the use of contraception until complete recovery, the fear that contraceptive methods may affect the newborn and that the baby may die for any reason and so there will urgent need for getting new pregnancy are barriers to uptake of immediate postpartum contraception.

In line with the proposal of the study to evaluate and provide knowledge about contraception and its modern methods, Brito et al. [36] detected low knowledge level and White et al. [37] reported no knowledge about contraceptive methods among pregnant teens in Brazil [36] and Cook Islands [37], and attributed this to low socioeconomic status [36] and suggested the need to expand comprehensive approaches to reproductive health education, increase access to long-acting reversible contraceptive methods, and decrease the stigma associated with accessing family planning services [37]. Thereafter, Mack et al. [4] through review of literature reported that continuation of contraceptives is low and recommended intensive counseling and educational information provision to improve the knowledge about hormonal contraceptive methods and importance of its continuation to avoid unplanned pregnancies. Also, Arnold-Rehring et al. [38] recommended the combination of education and process improvement to promote increased long-acting reversible contraceptives placement for adolescent women in primary care. Moreover, McNeely et al. [39] assured the feasibility of providing voluntary comprehensive family planning education and access to highly effective contraception for women especially those facing political, socioeconomic, and personal barriers to reproductive health care.

\section{Conclusion}

Ignorance, low financial status and cultural beliefs deleteriously affect the knowledge about contraception options and its methods, so direct interview with postpartum women is mandatory. The applied intervention succeeded to replenish women's knowledge about the benefits of using contraception. Primiparas had knowledge about contraception but their knowledge about methods is defi- 
cient or hazy. Contraception using IUD is the most acceptable method especially for primiparas.

\section{Conflicts of Interest}

The authors declare no conflicts of interest regarding the publication of this paper.

\section{References}

[1] Gonçalves, T.R., Leite, H.M., Bairros, F.S., Olinto, M.T.A., Barcellos, N.T. and Costa, J.S.D.D. (2019) Social Inequalities in the Use of Contraceptives in Adult Women from Southern Brazil. Revista de Saude Publica, 53, 28. https://doi.org/10.11606/S1518-8787.2019053000861

[2] Gupta, S., Ramsay, P., Mola, G., McGeechan, K., Bolnga, J., Kelly-Hanku, A. and Black, K.I. (2019) Impact of the Contraceptive Implant on Maternal and Neonatal Morbidity and Mortality in Rural Papua New Guinea: A Retrospective Observational Cohort Study. Contraception, 100, 42-47. https://doi.org/10.1016/j.contraception.2019.03.042

[3] Tisovic, K. and Amezcua, L. (2019) Women's Health: Contemporary Management of MS in Pregnancy and Post-Partum. Biomedicines, 7, 32. https://doi.org/10.3390/biomedicines7020032

[4] Mack, N., Crawford, T.J., Guise, J.M., Chen, M., Grey, T.W., Feldblum, P.J., Stockton, L.L. and Gallo, M.F. (2019) Strategies to Improve Adherence and Continuation of Shorter-Term Hormonal Methods of Contraception. Cochrane Database of Systematic Reviews, 4, CD004317. https://doi.org/10.1002/14651858.CD004317.pub5

[5] Szücs, M., Bitó, T., Csíkos, C., Párducz Szöllősi, A., Furau, C., Blidaru, I., Kapamadzija, A., Sedlecky, K., Bártfai, G. and Scientific Group of the Collaborating Centres (2017) Knowledge and Attitudes of Female University Students on Menstrual Cycle and Contraception. Journal of Obstetrics and Gynaecology, 37, 210-214. https://doi.org/10.1080/01443615.2016.1229279

[6] Harrington, L.A., Shaw, K.A. and Shaw, J.G. (2017) Contraception in US Service Women: Emerging Knowledge, Considerations, and Needs. Current Opinion in Obstetrics and Gynecology, 29, 431-436. https://doi.org/10.1097/GCO.0000000000000414

[7] Zuberi, S.K., Salman, S.H., Virji, R.N., Sana, S., Kumari, S. and Zehra, N. (2015) A Hospital-Based Comparative Study of the Knowledge, Attitudes and Practices of Family Planning among Women Belonging to Different Socio-Economic Status. Journal of Pakistan Medical Association, 65, 579-584.

[8] Sridhar, A., Chen, A., Forbes, E.R. and Glik, D. (2015) Mobile Application for Information on Reversible Contraception: A Randomized Controlled Trial. American Journal of Obstetrics \& Gynecology, 212, 774.e1-7. https://doi.org/10.1016/j.ajog.2015.01.011

[9] Satterwhite, C.L., French, V., Allison, M., Honderick, T. and Ramaswamy, M. (2019) Access to Contraception in Local Health Departments, Four Midwest States, 2017-2018. Contraception, 99, 363-367.

https://doi.org/10.1016/j.contraception.2019.02.009

[10] Lauring, J.R., Lehman, E.B., Deimling, T.A., Legro, R.S. and Chuang, C.H. (2016) Combined Hormonal Contraception Use in Reproductive-Age Women with Contraindications to Estrogen Use. American Journal of Obstetrics \& Gynecology, 215, 
330.e1-7. https://doi.org/10.1016/j.ajog.2016.03.047

[11] Horner-Johnson, W., Moe, E.L., Stoner, R.C., Klein, K.A., Edelman, A.B., Eden, K.B., Andresen, E.M., Caughey, A.B. and Guise, J.M. (2019) Contraceptive Knowledge and Use among Women with Intellectual, Physical, or Sensory Disabilities: A Systematic Review. Disability and Health Journal, 12, 139-154. https://doi.org/10.1016/j.dhjo.2018.11.006

[12] Glasier, A., Bhattacharya, S., Evers, H., Gemzell-Danielsson, K., Hardman, S., Heikinheimo, O., Lavecchia, C. and Somigliana, E. (2019) Contraception after Pregnancy. Acta Obstetricia et Gynecologica Scandinavica, 98, 1378-1385. https://doi.org/10.1111/aogs.13627

[13] WHO MEC (2015) Medical Eligibility Criteria for Contraceptive Use. 5th Edition, World Health Organization, Geneva. http://www.who.int/reproductivehealth/publications/familyplanning/MEC-5/en

[14] Division of Reproductive Health Center for Disease Control and Prevention (2016) US Medical Eligibility Criteria for Contraceptive Use. https://www.cdc $>$ mec $>$ summary

[15] Jatlaoui, T.C., Whiteman, M.K., Jeng, G., Tepper, N.K., Berry-Bibee, E., Jamieson, D.J., Marchbanks, P.A. and Curtis, K.M. (2018) Intrauterine Device Expulsion after Postpartum Placement: A Systematic Review and Metaanalysis. Contraception, 132, 895-905. https://doi.org/10.1097/AOG.0000000000002822

[16] Whitaker, R., Hendry, M., Aslam, R., Booth, A., Carter, B., Charles, J.M., Craine, N., Tudor Edwards, R., Noyes, J., Ives Ntambwe, L., Pasterfield, D., Rycroft-Malone, J. and Williams, N. (2016) Intervention Now to Eliminate Repeat Unintended Pregnancy in Teenagers (INTERUPT): A Systematic Review of Intervention Effectiveness and Cost-Effectiveness, and Qualitative and Realist Synthesis of Implementation Factors and User Engagement. Health Technology Assessment, 20, 1-214. https://doi.org/10.3310/hta20160

[17] Dewart, C.M., Serpico, J., Steiner, M.J. and Gallo, M.F. (2019) Electronic Interventions for Changing Knowledge, Attitudes, or Practices Regarding Contraception: A Systematic Review. Contraception, 100, 10-25. https://doi.org/10.1016/j.contraception.2019.04.004

[18] Spector, P.E. (1992) Summated Rating Scale Construction. Sage University Paper Series on: Quantitative Applications in the Social Sciences No 82. Sage, Newbury Park. https://doi.org/10.4135/9781412986038

[19] Hogmark, S., Klingberg-Allvin, M., Gemzell-Danielsson, K., Ohlsson, H. and Essén, B. (2013) Medical Students' Knowledge, Attitudes and Perceptions towards Contraceptive Use and Counselling: A Cross-Sectional Survey in Maharashtra, India. BMJ Open, 3, e003739. https://doi.org/10.1136/bmjopen-2013-003739

[20] Najafi, F., Rahman, H.A., Hanafiah, M., Momtaz, Y.A. and Ahmad, Z. (2012) Emergency Contraception: Knowledge, Attitudes and Practices among Married Malay Women Staff at a Public University in Malaysia. The Southeast Asian Journal of Tropical Medicine and Public Health, 43, 1512-1520.

[21] Opoku, B. and Kwaununu, F. (2011) Knowledge and Practices of Emergency Contraception among Ghanaian Women. African Journal of Reproductive Health, 15, 147-152.

[22] Olamijulo, J.A. and Olorunfemi, G. (2012) Knowledge and Practice of Contraception among Pregnant Women Attending the Antenatal Clinic in Lagos University Teaching Hospital. Nigerian Journal of Medicine, 21, 387-393.

[23] Ramathuba, D.U., Khoza, L.B. and Netshikweta, M.L. (2012) Knowledge, Attitudes 
and Practice of Secondary School Girls towards Contraception in Limpopo Province. Curationis, 35, 45. https://doi.org/10.4102/curationis.v35i1.45

[24] Elkalmi, R.M., Khan, M.U., Ahmad, A., Srikanth, A.B., Abdurhaman, N.S., Jamshed, S.Q., Awad, A.I. and Ab-Hadi, H.B. (2015) Knowledge, Awareness, and Perception of Contraception among Senior Pharmacy Students in Malaysia: A Pilot Study. Journal of Research in Pharmacy Practice, 4, 94-98. https://doi.org/10.4103/2279-042X.155760

[25] Ajong, A.B., Njotang, P.N., Kenfack, B., Yakum, M.N. and Mbu, E.R. (2016) Knowledge of Women in Family Planning and Future Desire to Use Contraception: A Cross Sectional Survey in Urban Cameroon. BMC Research Notes, 9, 347. https://doi.org/10.1186/s13104-016-2155-7

[26] Dut, R. and Al, R.A. (2019) A Brief Study on the Knowledge and Choice of Contraception Methods in Married Adolescent Girls. International Journal of Adolescent Medicine and Health. https://doi.org/10.1515/ijamh-2018-0091

[27] Kofinas, J.D., Varrey, A., Sapra, K.J., Kanj, R.V., Chervenak, F.A. and Asfaw, T. (2014) Adjunctive Social Media for More Effective Contraceptive Counseling: A Randomized Controlled Trial. Obstetrics \& Gynecology, 123, 763-770. https://doi.org/10.1097/AOG.0000000000000172

[28] Byker, T., Myers, C. and Graff, M. (2019) Can a Social Media Campaign Increase the Use of Long-Acting Reversible Contraception? Evidence from a Cluster Randomized Control Trial Using Facebook. Contraception, 100, 116-122.

[29] Gosavi, A., Ma, Y., Wong, H. and Singh, K. (2016) Knowledge and Factors Determining Choice of Contraception among Singaporean Women. Singapore Medical Journal, 57, 610-615. https://doi.org/10.11622/smedj.2015181

[30] Cohen, K.E., Has, P., Allen, R.H. and Matteson, K.A. (2019) An Exploratory Study of the Perception of Contraceptive Safety and Impact on Lactation among Postpartum Nurses at Women and Infants Hospital in 2017. Contraception, 100, 152-154.

[31] Castleberry, N.M., Stark, L., Schulkin, J. and Grossman, D. (2019) Implementing Best Practices for the Provision of Long-Acting Reversible Contraception: A Survey of Obstetrician-Gynecologists. Contraception, 100, 123-127. https://doi.org/10.1016/j.contraception.2019.03.053

[32] Vigoureux, S. and Le Guen, M. (2018) Current Knowledge on Contraceptive Knowledge in France: CNGOF Contraception Guidelines. Gynécologie Obstétrique Fertilité \& Sénologie, 46, 777-785. https://doi.org/10.1016/j.gofs.2018.10.005

[33] Alene, K.A. and Atalell, K.A. (2018) Contraceptive Use and Method Preference among HIV-Positive Women in Amhara Region, Ethiopia. BMC Women's Health, 18, 97. https://doi.org/10.1186/s12905-018-0608-y

[34] Shahabuddin, A.S., Nöstlinger, C., Delvaux, T., Sarker, M., Bardají, A., Brouwere, V.D. and Broerse, J.E. (2016) What Influences Adolescent Girls' Decision-Making Regarding Contraceptive Methods Use and Childbearing? A Qualitative Exploratory Study in Rangpur District, Bangladesh. PLoS ONE, 11, e0157664. https://doi.org/10.1371/journal.pone.0157664

[35] Willcox, M., King, E., Fall, E., Mubangizi, V., Nkalubo, J., Natukunda, S., Nahabwe, H., Goodhart, C. and Graffy, J. (2019) Barriers to Uptake of Postpartum Long-Acting Reversible Contraception: Qualitative Study of the Perspectives of Ugandan Health Workers and Potential Clients. Studies in Family Planning, 50, 159-178. https://doi.org/10.1111/sifp.12088

[36] Brito, M.B., Alves, F.S.S., Souza, M.Q. and Requião, S.R. (2018) Low Level of Knowledge of Contraceptive Methods among Pregnant Teens in Brazil. Journal of 
Pediatric and Adolescent Gynecology, 31, 281-284.

https://doi.org/10.1016/j.jpag.2017.12.008

[37] White, A.L., Mann, E.S. and Larkan, F. (2018) Contraceptive Knowledge, Attitudes, and Use among Adolescent Mothers in the Cook Islands. Sexual \& Reproductive Healthcare, 16, 92-97. https://doi.org/10.1016/j.srhc.2018.02.004

[38] Arnold-Rehring, S.M., Reifler, L.M., Seidel, J.H., Glenn, K.A. and Steiner, J.F. (2019) Implementation of Recommendations for Long-Acting Contraception among Women Aged 13-18 in Primary Care. Academic Pediatrics, 19, 572-580. https://doi.org/10.1016/j.acap.2019.03.009

[39] McNeely, C.A., Hutson, S., Sturdivant, T.L., Jabson, J.M. and Isabell, B.S. (2019) Expanding Contraceptive Access for Women with Substance Use Disorders: Partnerships between Public Health Departments and County Jails. Journal of Public Health Management and Practice, 25, 229-237.

https://doi.org/10.1097/PHH.0000000000000850 
Appendix 1

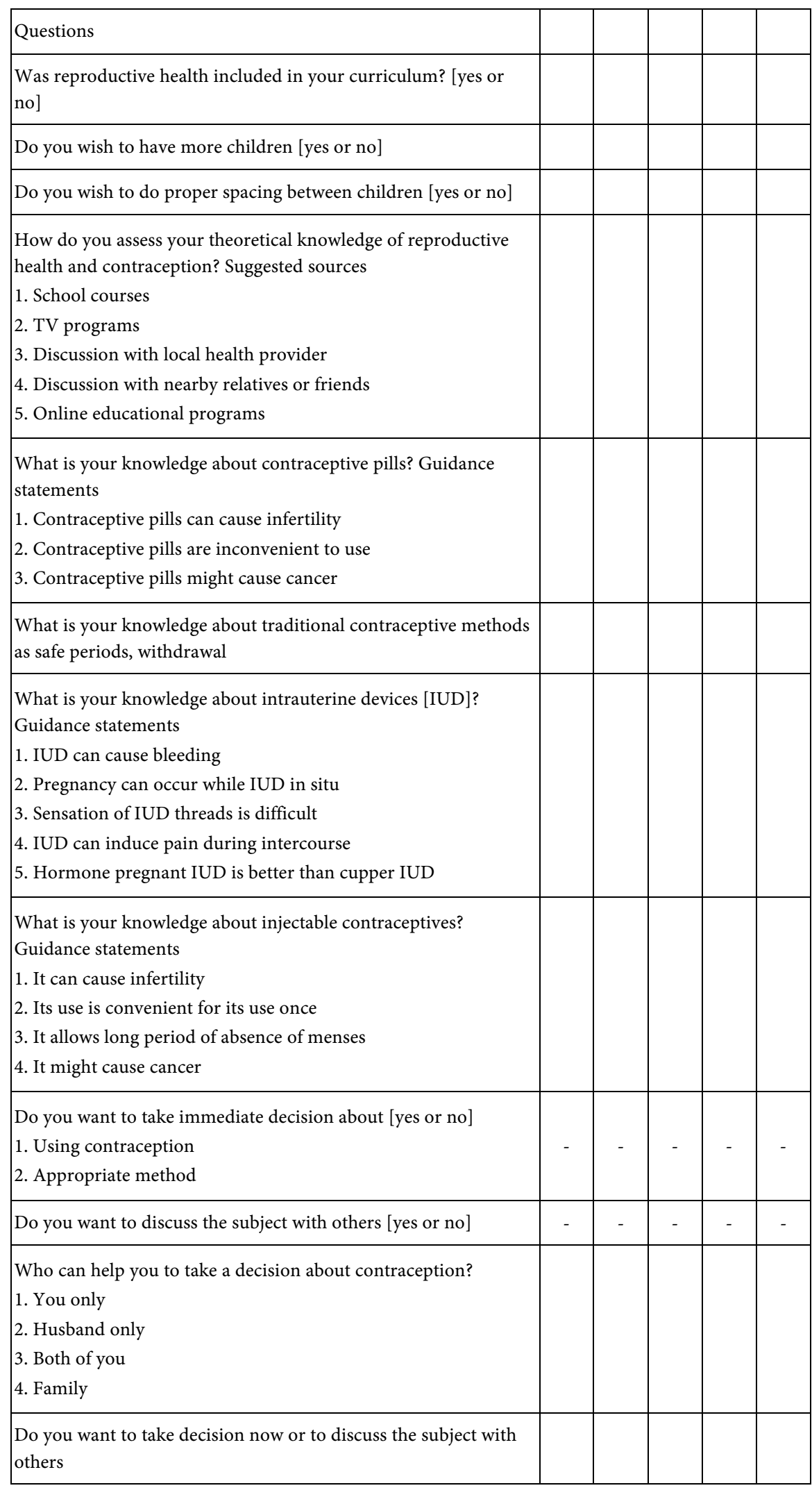

